Dan Podjed

\title{
Skupnizacija kot seštevek skupnosti in organizacije: primer ornitološkega in naravovarstvenega društva
}

\begin{abstract}
Ključne besede: organizacija, skupnost, omrežje, ornitološko društvo, varovanje narave
\end{abstract}

DOI: 10.4312 /ars.8.1.99-117

\section{Uvod}

Pri analizi in urejanju procesov $\mathrm{v}$ organizacijah - pa naj bodo pridobitne ali nepridobitne, vladne ali nevladne - skušamo razmerja med ljudmi razumeti, osmisliti in predstaviti na urejen, strukturiran način. Pri tem si pogosto pomagamo z organigrami kot prikazi razmerij v podjetjih, društvih, zavodih in drugih oblikah sodelovanja. Takšne upodobitve imajo navadno obliko piramide, v kateri se od vodilne osebe na vrhu spuščamo do nižjih ravni odgovornosti, kjer se nahaja vse več "podrejenih « sodelavcev (glej na primer Mintzberg, 1979; Mintzberg, van der Heyden, 1999, kjer so predstavljene še alternativne upodobitve organizacijskih struktur).

Razmerja v organizacijah pa so dejansko vse prej kot pregledna. To so ugotavljali že v poznih dvajsetih in zgodnjih tridesetih letih 20. stoletja, ko so v ZDA izvedli t. i. raziskavo Hawthorne (Schwartzman, 1993), v kateri so strokovnjaki z različnih področij - od sociologov in psihologov do antropologov - pod vodstvom avstralskega psihologa in sociologa Eltona Maya analizirali delovne procese v čikaški podružnici podjetja Western Electrics. Med drugim so ugotovili, da $\mathrm{v}$ tovarni poleg formalne organizacije, v kateri so interakcije jasno določene ter urejene s pravili in uredbami, soobstaja še bolj prikrita neformalna organizacija, ki so jo ljudje ustvarili mimo predpisov in zamisli vodstva. Izkazalo se je tudi, da so transparentni in sistematizirani organigrami, ki naj bi uprizarjali razmerja v organizacijah, bolj ali manj idealnotipske predstave (primerjaj Schutz, 1972), organizacijska realnost, ki jo ustvarjamo, pa je dejansko kompleksna ter bolj spominja na prepleteno in neurejeno omrežje kot na urejeno "piramido« (Molina, 2006). Da je situacija še nekoliko bolj zamotana, je takšna neformalna struktura ameboidna, dinamična in pogosto neločljivo prepletena $\mathrm{Z}$ »organizacijskim okoljem «. ${ }^{1}$

1 S podobne perspektive je družbena razmerja v Burmi obravnaval antropolog Edmund Leach (1993), 
$\mathrm{V}$ pričujočem prispevku ${ }^{2}$ skušam predstaviti podobno kompleksno in dinamično organizacijsko strukturo, in sicer na primeru Društva za opazovanje in proučevanje ptic Slovenije (DOPPS), ki sem ga proučeval v raziskovalnem projektu EuMon (2005-2008). ${ }^{3}$ Po dveletni etnografski raziskavi (2006-2007), med katero sem se posvetil tako formalnim kot neformalnim povezavam v DOPPS, se je izkazalo, da ima ta organizacija svojevrstno strukturo, ki je ne moremo upodobiti s preprostim dvodimenzionalnim organigramom. $\mathrm{V}$ društvu sem namreč naletel na preplet dveh modelov sodelovanja, in sicer hierarhične organizacije $s$ "piramidalno in pregledno strukturo ter horizontalne skupnosti, $\mathrm{v}$ kateri se razmerja nenehno na novo definirajo. Kot bomo videli $\mathrm{v}$ prispevku, lahko takšno hibridno organizacijsko strukturo predstavimo in upodobimo kot »seštevek" organizacije in skupnosti.

\section{Teoretska izhodišča}

$\mathrm{V}$ prispevku uporabljam in prepletam tri termine: organizacija, skupnost in omrežje. Z njimi skušam pojasniti, kako nastane hibridna organizacijska struktura, ki je sočasno urejena in neurejena, stabilna in dinamična. Pri tem izhajam iz antropoloških in socioloških definicij, dopolnjujem pa jih z razlagami organizacijskih teoretikov.

Beseda organizacija, ki je v središču razprave, ima po razlagi iz Slovarja slovenskega knjižnega jezika številne pomene. Po eni strani je to glagolnik od organizirati (primer: »ima smisel za organizacijo«), po drugi pa značilnost oziroma stanje organiziranega. Druga definicija razloži, da organizacija pomeni nenaključno ureditev komponent ali delov, ki so povezani tako, da tvorijo sistem, ki ga lahko identificiramo kot enoto. Poleg tega beseda opisuje sekvenčno in/ali prostorsko entiteto, v kateri so znanje, podatki, ljudje ali drugi elementi namensko urejeni, pa tudi skupino ljudi, ki sistematično sledijo skupnemu cilju. Podobna je prevladujoča definicija številnih organizacijskih teoretikov, ki pojasnjujejo, da organizacija opisuje skupino ljudi s skupnim ciljem, poslanstvom ali programom (Ford, Armandi, Heaton, 1988; Katz, Kahn, 1983; Robbins, 1996). Po etnografski raziskavi, med katero se je izkazalo, da so skupni cilji

ki je na videz transparentne strukture opisal kot idealizirane modele, ki so dejansko fluidni, nestabilni in dinamični, njihovi predstavniki pa lahko sočasno zasedejo več pozicij v različnih sistemih in prehajajo med njimi.

2 Zgodnja različica prispevka je bila objavljena v poglavju knjige Opazovanje opazovalcev: Antropološki pogled na ornitološko organizacijo (Podjed, 2011), ki je izšla pri Znanstveni založbi Filozofske fakultete Univerze v Ljubljani. V tem prispevku so dodani etnografski primeri, teoretski okvir ter uvod in sklep. Skici, objavljeni v prispevku (slika 1 in 2), je oblikoval Jure Preglau, tehnični urednik založbe. Objavljamo ju s soglasjem založbe.

3 Projekt $\mathrm{z}$ naslovom EU-wide Monitoring Methods and Systems of Surveillance for Species and Habitats of Community Interest (EuMon) je potekal v 6. okvirnem programu EU. V njem smo se posvetili naravoslovnim in družboslovnim vidikom spremljanja stanja v naravi. Spletna stran projekta: http:// eumon.ckff.si/. 
in poslanstvo DOPPS bolj kot ne ideal, interpretacij teh izhodišč sodelovanja oziroma »temeljnih predpostavk« (primerjaj Schein, 1992) pa je lahko veliko, se bolj nagibam $\mathrm{k}$ definiciji Barbare Czarniawske-Joerges, ki organizacije razume kot »omrežja kolektivnih dejavnosti, ki skušajo oblikovati svet in človeška življenja« (1992, 32), ter dodaja, da takšna omrežja nimajo jasno določenih meja, temveč se te nenehno na novo vzpostavljajo, organizacija in njeno okolje pa se neločljivo prepletata. Tomoko Hamada podobno pojasnjuje, da je za organizacijsko življenje značilna fluidnost, ne pa linearnost, saj se dejanja in odločitve posameznikov ves čas »zaletavajo ob stene spreminjajočega se labirinta pomenov, položajev, statusov, preprek in pasti« (Hamada, 1994, 26). Po njenem mnenju ni pomembno le to, kar se v organizaciji zgodi, temveč tudi, kako dogodke interpretiramo. Isti dogodki imajo zaradi različnih kognitivnih shem različne pomene, to pa vodi $\mathrm{v}$ kontradikcije in konflikte, ki niso nujno destruktivni, temveč lahko pomagajo soustvarjati kompleksno organizacijsko realnost (1994, 27). Tudi organizacijski antropolog Martin Parker, ki v svojih analizah sledi predvsem t. i. postmoderni paradigmi, se odmika od iskanja enovitosti in konsenza $\mathrm{v}$ organizacijah ter pravi, da organizacija in njena kultura predstavljata in uprizarjata »nenehen konflikten proces utrjevanja razlik v skupinah in med njimi« (Parker, 2000, 233). Namesto $z$ enovitostjo se $\mathrm{v}$ organizacijskem kontekstu srečujemo z neurejenostjo (ali navidezno urejenostjo) ter konflikti in spopadi, ki potekajo med podkulturami, frakcijami itd. Zato sodobni raziskovalci organizacije razumejo kot vse manj urejene in organizirane ter vse bolj spremenljive, kompleksne ali celo kaotične entitete, od statičnega, stabilnega in konsenzualnega stanja pa so se definicije premaknile k opisom dinamike, procesualnosti in tvornosti. V tem skoraj "antiorganizacijskem" smislu (primerjaj Parker, 2000) organizacijo razumem tudi sam in jo zato obravnavam kot idealnotipsko predstavo o redu in skupnih predpostavkah, od katere se posamezniki bolj ali manj oddaljujejo, hkrati pa se po njej orientirajo in z njo identificirajo.

Naslednji izraz, ki je pomemben za to razpravo, je skupnost. Anthony P. Cohen $(1985,11)$ opozarja, da gre za eno od besed, s katerimi radi »opletamo« v vsakdanjem sporazumevanju in je $\mathrm{v}$ takšni rabi zlahka razumljiva, ogromno težav pa povzroča $\mathrm{v}$ družboslovnem in humanističnem diskurzu. Dodatne težave pa se pojavljajo predvsem zaradi dihotomnih opredelitev termina, ki ga je sociolog Ferdinand Tönnies (1999) postavil kot kontrapunkt družbe (Gesellschaft), ki naj bi predstavljala k učinkom in ciljem usmerjeno skupino ljudi s konsenzom o sodelovanju; skupnost (Gemeinschaft) pa je po njegovem mnenju entiteta, v kateri so ljudje povezani, solidarni in složni zaradi prepričanja o skupni pripadnosti. Podobno distinkcijo so ohranjali nekateri ključni družboslovni teoretiki, med njimi Émile Durkheim (1997), ki je razlikoval med mehansko in organsko solidarnostjo, Max Weber (1978), ki je pisal o skupnostnih in družbenih razmerjih, Georg Simmel (1971), ki je primerjal mestne in podeželske 
odnose ... V tem prispevku bom tovrstne dihotomije skušal preseči in omiliti ter predstaviti »nianse« med skrajnostma, pri čemer bom skupnost obravnaval predvsem kot skupino ljudi, ki občutijo medsebojno povezanost in solidarnost, ti pa se navadno vzpostavljata na podlagi primerjanja in razlikovanja $\mathrm{z}$ drugimi skupnostmi ter (re) definiranja ločnic med njimi.

Tretji temeljni pojem, ki ga uporabljam v prispevku, je omrežje. O smiselnosti uvajanja in uporabe tega termina pri analizi družbenih skupin so razpravljali številni sociologi in antropologi (na primer Boissevain, Mitchell, 1973; Granovetter, 1973; Mitchell, 1969, 1974; glej tudi Wolfe, 1978, kjer je objavljen eden prvih antropoloških pregledov te teme), med njimi tudi Alfred Radcliffe-Brown, ki je že v prvi polovici prejšnjega stoletja poudaril, da smo ljudje povezani v »kompleksno omrežje družbenih razmerij «(Radcliffe-Brown, 1940: 2). V tem prispevku omrežje razumem predvsem kot dinamično odprto družbeno strukturo (Castells, 2003, 470-471), ki jo deloma enačim s skupnostjo, in sicer predvsem zato, ker lahko oba pojma predstavljata kontrapunkt urejeni organizaciji. Ob tem se zavedam, da med tema pojmoma ne moremo postaviti enačaja, saj je skupnost vedno zamejena - pa četudi zgolj v predstavah (primerjaj Anderson, 2003) - ter povezuje ljudi s podobnimi izhodišči in interesi, medtem ko je omrežje odprto in fleksibilno, njegove meje so nejasne, skupni interesi pa niso bistveni za povezovanje (glej na primer Green, Harvey, Knox, 2005). Kljub temu menim, da obe obliki sodelovanja izhajata iz podobnih temeljnih predpostavk, in sicer predvsem iz egalitarnosti oziroma horizontalnega povezovanja.

Kaj pa se zgodi, če se različne oblike sodelovanja prepletejo med sabo? Martin Parker (1998) se je ukvarjal s takšnimi »hibridi« in idejno zasnoval družbeno obliko, ki gravitira k idealizirani skupnosti, hkrati pa ohranja strukturiranost organizacije - zanjo lahko zato uporabimo izraz skupnizacija. ${ }^{4}$ Takšna družbena oblika je, kot pravi Parker, strukturirana in organizirana ter hkrati utemeljena na rudimentarni pripadnosti in solidarnosti njenih članov. V skupnizaciji je meja med delom in prostim časom zabrisana, podobno nejasna pa je v njej tudi ločnica med zasebnim in javnim (ali službenim) prostorom, saj lahko »obstaja tam, kjer ljudje mislijo, da obstaja, kamorkoli jo že umesti intersubjektivna skupnostna prepoznava «(Parker, 1998, 84). Hierarhična razmerja v njej so zreducirana, člani so enakovredno nagrajeni, poleg tega pa ima vsak enak »delež« v kolektivni produkciji. Za skupnizacijo je značilno še, da se vanjo rekrutira predvsem enako misleče

4 Z izrazom skupnizacija prevajam Parkerjev neologizem orgunity. S prevodom, s katerim sem imel precej težav, sem skušal v slovenskem jeziku združiti dve besedi (skupn-ost in organ-izacija) ter ohraniti izhodiščni pomen skovanke (org-anisation in comm-unity). Sicer se zavedam, da bi bila morda bolj "pravilna« kakšna druga beseda, ki bi se začela s korenom besede organizacija in sklenila s skupnostjo (na primer orgupnost), a menim, da je bolj pomembno poiskati dovolj ustrezen in uporaben izraz kot »posiljevati« jezik s čim bolj natančnim prevodom. 
ljudi, zaradi česar ne pride do prevelikega razhajanja med interesi in nejasnega opredeljevanja, kdo smo Mi in kdo so Drugi.

Parker predstavi tri možnosti za udejanjenje - ali propad - svojega idejnega konstrukta. Prvič, lahko da je vse skupaj utopična zamisel brez vsakršne racionalne podlage, ki ne bo nikoli uresničljiva. Drugič, morda so te zamisli zgolj nadaljevanje komunizma, ki se je v praksi večkrat izkazal za precejšnjo polomijo. ${ }^{5}$ Tretja možnost pa je, da skupnizacija dejansko pomeni nov model povezovanja ljudi in strukturiranja družbenih razmerij, ki je lahko vsaj deloma uresničljiv in uspešen. V tem prispevku se nagibam $k$ tretji možnosti in iščem značilnosti skupnizacije $v$ društvu DOPPS, a ne v njegovi prvotni obliki, temveč v hibridni »izvedenki«, ki je nastala po burni transformaciji ob koncu prejšnjega stoletja. Ob tem skušam Parkerjeve in druge koncepte kritično pretresti ter analizirati prednosti in pomanjkljivosti njihovega udejanjenja na konkretnem primeru.

\section{Nastanek in preoblikovanje DOPPS}

Decembra 1979 so v Ljubljani sklicali ustanovno skupščino DOPPS, ki se je je udeležilo 76 ljudi. Ustanovitev društva je bila namenjena predvsem povezovanju dotlej razkropljenih posameznikov, ki so se v Sloveniji ukvarjali z opazovanjem in popisovanjem ptic. Eden izmed ključnih pobudnikov je bil karizmatični Iztok Geister (glej Podjed, 2010), ki je že pred ustanovitvijo društva skušal povezati prostovoljce in profesionalne ornitologe z zadosti znanja za zbiranje podatkov o pticah, na podlagi katerih bi lahko pripravili slovenski ornitološki atlas.

Kmalu po ustanovitvi DOPPS so se začeli prvi poskusi širjenja dejavnosti zunaj republiških meja in ustanavljanja jugoslovanske zveze ornitoloških društev, ki naj bi povezala ornitologe na ravni tedanje države. Tri leta kasneje, torej leta 1983, so že priredili prvo konferenco jugoslovanskih ornitologov; takšne konference so odtlej potekale vsako leto - vse do leta 1988. Leta 1987 so uradno oblikovali Zvezo ornitoloških društev Jugoslavije (ZODJ), ki je leto zatem postala članica in nacionalna sekcija Mednarodnega sveta za zaščito ptic (International Council for Bird Preservation oziroma ICBP), ki se je kasneje preimenoval v BirdLife International. ${ }^{6}$ Sočasno $\mathrm{s}$ povezovanjem $s$ tujino se je začela notranja delitev društva, na kar je vplivala tudi rast organizacije, katere članstvo se je zgolj v štirih letih potrojilo. Da bi razpršili upravljanje

5 Še bolj kot na komunizem zamisel skupnizacije spominja na organiziranje delovnih procesov v samoupravnem socializmu nekdanje Socialistične federativne republike Jugoslavije, ki je v praksi prav tako imel precej pomanjkljivosti (glej na primer Podjed, 2006, kjer piše več o postmodernih organizacijah, ki imajo precej skupnega s skupnizacijo).

6 Ta mednarodna organizacija ima več kot 2,5 milijona članov, 10 milijonov podpornih članov in več kot 4000 zaposlenih (BirdLife, 2014). 
in odločanje ter spodbudili lokalne iniciative, so v izvršilnem odboru DOPPS regionalizacijo posebej poudarjali - vsako leto od 1984 do 1987 so, denimo, sprejeli sklep, da bodo pričeli "priprave za ustanovitev ornitoloških društev širom po Sloveniji, ki naj bi se združila v zvezo (IO DOPPS, 1984, 69; 1986, 24; 1987, 28). Regionalizacija pa sprva ni potekala povsem po načrtu, saj je leta 1983 v Kopru nastalo ornitološko društvo Ixobrychus, ki je registrirano še danes, a ni več posebej aktivno. To društvo naj bi se po nekaterih zamislih pridružilo DOPPS, ta pa naj bi postal krovna organizacija na republiški ravni. Namesto tega je Ixobrychus ostal samostojno društvo, pobude za pridružitev nacionalni organizaciji pa niso bile uspešne. Regionalizacija je odtlej potekala bolj v skladu s prvotnimi zamislimi DOPPS, le da so namesto samostojnih društev začele vznikati regionalne sekcije. Leta 1989 so ustanovili Štajersko sekcijo, leta 1995 Notranjsko sekcijo, leta 1997 Ljubljansko sekcijo, leta 2006 Severnoprimorsko sekcijo in leta 2009 Pomursko sekcijo. Poleg teh regionalnih sekcij je leta 2005 nastala še Mladinska sekcija, ki povezuje mlajše člane in njihove dejavnosti.

Leta 1991 so se sočasno $\mathrm{z}$ razpadom Jugoslavije pretrgale ali vsaj ošibile vezi med društvi iz nekdanjih jugoslovanskih republik. V tem prelomnem letu je DOPPS prekinil tudi razmerje z Zvezo ornitoloških društev Jugoslavije (ZODJ) ter začel iskati nove povezave $\mathrm{v}$ tujini in si prizadevati za priznanje na mednarodni ravni. Iskanje navez in zavezništev je olajšalo predhodno sodelovanje $\mathrm{z}$ organizacijami, ki so bile članice ICBP, recimo z mladinsko sekcijo britanskega Kraljevega društva za zaščito ptic (Royal Society for Protection of Birds oziroma RSPB). DOPPS je leta 1993 pridobil še predstavniški status v zvezi BirdLife International in leta 1996 status partnerja pripravnika. Leta 1998 so izvedli še simbolno povezavo s to mednarodno zvezo in akronimu društva dodali ime organizacije, ki so se ji pridružili, ${ }^{7}$ leta 2001 pa je DOPPS naposled pridobil status polnopravnega partnerja v organizaciji BirdLife.

$\mathrm{V}$ devetdesetih letih 20. stoletja sta društvo zaznamovala še sprememba »ideologije«, ki se je najbolj očitno odrazila pri prehodu od opazovanja ptic k varovanju narave (glej Podjed, 2013, kjer piše več o tem paradigmatskem prehodu) ter pri profesionalizaciji nekaterih društvenih dejavnosti ob podpori sponzorjev - predvsem največjega slovenskega operaterja mobilne telefonije Mobitel (glej Kimovec, 2008, kjer je objavljena analiza sponzorskega sodelovanja). Po letu 2000 je število članov stagniralo ali celo nekoliko upadlo, naglo pa je zrasel profesionalni del, t. i. Pisarna DOPPS, v kateri je bilo leta 2014 več kot 20 zaposlenih.

7 Uradno ime društva je odtlej DOPPS - BirdLife Slovenia, s čimer so po svoje "prikrili« nekdanjo temeljno dejavnost - opazovanje in proučevanje ptic - ter poudarili prehod k varovanju narave. $\mathrm{Na}$ to je v nekem intervjuju opozoril osrednji ustanovitelj društva Iztok Geister in dejal, da je odsotnost varstva narave v imenu društva postala ovira, ko je "pridobitniško usmerjena struja mlajših ornitologov" pričela sklepati povezave z organizacijo BirdLife. "Zato so hoteli sprva spremeniti ime, kasneje pa so se zadovoljili s kratico DOPPS, ki je ta manko prikrila, « je pojasnil Geister (po Ahačič, 2008, 39). 
Rast poklicnega dela društva je najprej omogočilo sodelovanje z glavnim pokroviteljem, torej podjetjem Mobitel, zatem pa še pridobitev sredstev iz različnih projektov in evropskega programa LIFE Natura, ki so jih namenili za renaturacijo Škocjanskega zatoka v Kopru in varovanje kosca (Crex crex) v Sloveniji. Leta 2005 je bil DOPPS celo edina slovenska organizacija, ki je pridobila dva projekta LIFE v skupni vrednosti skoraj 1,4 milijona evrov. Oba projekta sta bila za društvo izjemno pomembna, saj so leta 2004 več kot 40 odstotkov sredstev za profesionalno ekipo pokrili iz teh virov (Šalaja, 2004, 25), podobno pa je bilo tudi leta 2007, ko so evropska sredstva pomenila skoraj polovico društvenega proračuna.

Poleg naravovarstvenih projektov, ki so od preloma stoletja osrednja društvena dejavnost, se vDOPPS še vedno ukvarjajo z izhodiščno dejavnostjo, torej z opazovanjem in proučevanjem ptic. Od leta 2002 med drugim izvajajo pomemben projekt, ki je primerljiv z začetnimi prizadevanji članov in članic ob koncu sedemdesetih let, ko so začeli izvajati množične popise za ornitološki atlas Slovenije. Poleg popisov v društvu prirejajo ogromno različnih dogodkov - od izobraževanj in predavanj do naravovarstvenih akcij -, ki so preštevilni, da bi jih evidentiral v tem pregledu. Vsekakor pa vse te dejavnosti sooblikujejo kulturo in strukturo organizacije, v kateri se ljubiteljstvo prepleta s strokovnostjo, prostovoljstvo pa s profesionalizmom.

\section{Transformacija: od »družine« do skupnizacije}

Kot smo videli, je DOPPS potreboval več kot dvajset let za preobrazbo iz prostovoljskega ornitološkega društva $\mathrm{v}$ organizacijo, ki se ne ukvarja več le $\mathrm{z}$ opazovanjem ptic, temveč tudi - ali celo predvsem $-\mathrm{z}$ varovanjem narave. $\mathrm{V}$ tem času so se spreminjala tudi razmerja v organizaciji. V začetnem obdobju, torej ob ustanovitvi leta 1979, lahko DOPPS razumemo kot nestrukturirano skupnost, katere člani so bili bolj ali manj enakopravni, hierarhična razmerja pa so bila fleksibilna in nejasna. Organizacija je bila spočetka nekakšen približek Turnerjeve (1974) communitas kot rudimentarno strukturiranega in nediferenciranega modela, $\mathrm{v}$ katerem družbena topografija izgine. Takšno amorfno stanje povzemajo besede ustanovnega člana, ki je dejal, da nekdaj »ni bilo nekih povelj. Vse je bilo bolj dogovorno: kako bi pridobili člane, kako bi obogatili revijo ... « Takšna enakopravnost je bila v začetnem obdobju sicer izrazita, ne pa absolutna, saj so niti v rokah vendarle držali ustanovni člani DOPPS in njihovi (na)sledniki, a to pravzaprav ni v nesoglasju z definicijo communitas, saj tudi ta opisuje skupnost "enakih posameznikov, ki se podredijo obči avtoriteti obrednih starešin « (Turner, 1974, 82). Med njimi je bil najpomembnejši osrednji ustanovitelj Iztok Geister, ki ga številni sogovorniki še vedno predstavljajo kot »očeta društva«. 
Podobno je s prvim društvenim obdobjem, ki se ga nekateri starejši člani idealizirano in verjetno nekoliko "umišljeno" spominjajo kot čas velike družine. Obdobje opisujejo kot »dobre stare čase» (primerjaj Brumen, 2001), ko so bili vsi enakopravni in je bil bolj živ »društveni duh«, zaznamovale pa so ga solidarnost, motiviranost za delo in neformalna komunikacija med člani. To obdobje je trajalo skoraj dve desetletji, v DOPPS pa so v tem času zabeležili izjemno rast števila članov, ki jih je bilo sredi osemdesetih let 20. stoletja približno 250, ob prelomu stoletja pa že skoraj tisoč, nakar se je rast nekoliko ustavila. Ob koncu osemdesetih in v devetdesetih letih se je zaradi povečanega števila članov organizacijska struktura DOPPS že bolj formalizirala, $v$ društvu pa sta se oblikovali dve struji, ki sta imeli nasprotujoča si mnenja o temeljnih dejavnostih. Starejši člani so se zbrali predvsem okrog revije Acrocephalus, ki jo je takrat še vedno urejal osrednji ustanovitelj društva, mlajši pa so, kot je opisal eden izmed ustanovnih članov, postopno »zavzeli« društvene organe. V nekdaj enoviti ekipi so se zaradi različnih pogledov na prihodnost in medgeneracijskih trenj pojavile prve razpoke. Skupina mladih je vse bolj poudarjala pomen naravovarstvenih akcij, imela pa je tudi drugačno vizijo o tem, kakšni naj bi bili podoba in vsebina osrednje društvene revije. Poljudni članki bi po njihovem mnenju morali izhajati v posebni reviji, Acrocephalus pa naj bi postal znanstvena publikacija. Starejši so nasprotno menili, da je bolje, če tako poljudne kot znanstvene vsebine ostanejo v eni reviji, zagovarjali pa so še ohranitev »izvirnih« dejavnosti, torej opazovanja ptic.

Napetosti so se stopnjevale do leta 1999, ko se je zgodil nenaden obrat. Osrednji teoretik organizacij Edgar Schein takšno transformacijo posrečeno opiše, ko pravi, da v organizacijah pogosto "pride do spopada med »konservativci«, ki jim je ustanovitvena kultura všeč, in »liberalci« oziroma »radikalci«, ki hočejo spremeniti kulturo, deloma tudi zato, ker bi radi povečali lastno pozicijo moči« (Schein, 1992, 310). Nekdaj aktiven član, ki se je kasneje posvetil profesionalni biološki karieri v neki drugi organizaciji, je obrat opisal kar kot »revolucijo«. Zgodovino društva lahko zato po njegovem mnenju razdelimo na dve fazi: "Prva je bila od začetka in dokler so še ti ustanovitelji niti v rokah držali, potem pa je ta ... Niti ni bila evolucija, je bila bolj revolucija, ki se je zgodila. Od takrat je to čisto drug DOPPS."

Povod za nenadne spremembe je bil na videz banalen spor o sredstvih, ki jih je društvo namenjalo za revijo Acrocephalus, po katerem je izvršilni odbor »očeta društva odstavil z mesta odgovornega urednika revije. Osrednji pobudnik DOPPS je po tem dogodku izgubil formalno in neformalno pozicijo moči v društvu, zato je prekinil stike $z$ organizacijo. Njegov odhod in nenadne spremembe pa niso bili povsem nepričakovani, saj je veliko predhodnih dogodkov nakazovalo, da se v organizaciji pripravlja prelom s starimi vrednotami in načinom dela. Približevanje zvezi BirdLife International, pokroviteljstvo Mobitela in druge novosti so kazale na usmeritev 
$\mathrm{k}$ varovanju narave in bolj profesionalnemu delu, kar sta bila temeljna vzroka za paradigmatski razkol. Ena frakcija je namreč zagovarjala profesionalizacijo društva in naravovarstvene dejavnosti, drugi pa so vztrajali, da mora poudarek ostati na delu prostovoljcev, ki naj se še naprej ukvarjajo predvsem z opazovanjem in proučevanjem ptic.

Scenarijev za nadaljnji razvoj je bilo na prelomni točki več. Društvo bi se lahko po prvi varianti vrnilo $\mathrm{k}$ izhodiščem in se še naprej ukvarjalo predvsem s popisi ptic in drugimi ornitološkimi dejavnostmi. Druga pot bi lahko privedla do razcepa organizacije na prostovoljski in profesionalni del, o čemer so v DOPPS dejansko razmišljali. Tretja opcija, ki se je tudi udejanjila, pa je bil soobstoj prostovoljskih in profesionalnih dejavnosti v enotnem okviru, kar je pomenilo, da se je moral izoblikovati hibridni model, utemeljen na nekoliko utopični zamisli, da lahko profesionalne in prostovoljske ter ljubiteljske in strokovne dejavnosti soobstajajo v eni instituciji podobno kot v skupnizaciji, ki jo je predstavil Martin Parker.

\section{Društvo kot skupnizacija}

Katere lastnosti skupnizacije, kot si jo je zamislil Parker, lahko identificiramo v DOPPS? Precej članov, predvsem najbolj dejavnih, je prepričanih o kolektivni pripadnosti društvu, ki se zavzema za njihove osebne vrednote: varovanje ptic in narave. Poleg tega je ločnica med delom in prostim časom v DOPPS dejansko zabrisana, saj se zaposleni redno udeležujejo prostočasnih dejavnosti, njihovo delo pa je bilo (in je še vedno) predvsem hobi (več o tem v naslednjem razdelku). Poleg časovne komponente je nejasna tudi prostorska dimenzija, saj DOPPS težko umestimo v prostor in jasno določimo, kje se nahaja. Že res, da je osrednja pisarna društva v Ljubljani, a tja prihajajo na delo predvsem zaposleni, preostali člani - in tudi nekateri zaposleni - pa so razkropljeni po Sloveniji. Hierarhična struktura DOPPS sicer ni povsem ploska, saj imajo predsednik, podpredsednik in upravni odbor v rokah veliko pooblastil in avtonomije za izvajanje in spreminjanje društvenih usmeritev, kljub temu pa je najvišji društveni organ skupščina, ki sprejme ali zavrne pobude upravnega odbora in izvoli njegove člane, poleg tega pa se ljudje na vodstvenih položajih redno izmenjujejo. Pri enakopravnosti nagrajevanja se pojavi nekoliko več težav, saj prostovoljci za svoje delo niso plačani, zaposleni pa so, iz česar izvirajo nekatera trenja in nesporazumi. Zadnja lastnost skupnizacije, ki jo navaja Parker, je povezovanje enako mislečih posameznikov; tudi to lahko identificiramo v DOPPS. Izbora "pravovernih « članov sicer ne izvajajo vodilni v organizaciji, temveč je selekcija pravzaprav samodejna, saj se v društvo včlanijo ljudje, ki so jim blizu ptice in narava, zaradi česar sledijo društvenemu poslanstvu in kodeksu, ki na prvo mesto postavljata 
varovanje ptic in njihovih življenjskih prostorov. Kot vidimo, lahko trem od šestih značilnosti skupnizacije v primeru DOPPS v celoti pritrdimo, preostalim trem pa vsaj deloma (tabela 1). Iz tega lahko sklepamo, da dejansko obstaja približek družbene entitete, ki premošča vrzel med skupnostjo in organizacijo.

Tabela 1: Značilnosti skupnizacije v DOPPS.

\begin{tabular}{|l|c|c|}
\hline Značilnost & Skupnizacija & DOPPS \\
\hline 1. Prepričanje o kolektivni pripadnosti. & DA & DELOMA \\
\hline 2. Zabrisana ločnica med delom in prostim časom. & DA & DA \\
\hline 3. Nejasno prostorsko definirana organizacija. & DA & DA \\
\hline 4. »Ploska« hierarhija in »rotacija« vodilnih članov. & DA & DELOMA \\
\hline 5. Egalitarnost pri nagrajevanju. & DA & DELOMA \\
\hline 6. Pridobivanje enako mislečih posameznikov. & DA & DA \\
\hline
\end{tabular}

\section{Delo kot prosti čas}

Na podlagi etnografske raziskave v DOPPS ugotavljam, da je eden od temeljnih pogojev za vzpostavitev skupnizacije kot prepleta bolj formalne, urejene organizacije in neformalne, nestrukturirane skupnosti razblinjanje ločnice med delom in prostim časom - to pa se navadno zgodi $\mathrm{z}$ angažirano in redno udeležbo pri prostovoljskih dejavnostih. Kanadski sociolog Robert A. Stebbins (2002, 2006) to označi z izrazom resen prosti čas (angl. serious leisure) in ga definira kot sistematično prizadevanje amaterjev ali prostovoljcev, ki je za udeležence tako tehtno in zanimivo, da se pogosto usmerijo v napredovanje kariere, ko pridobivajo in izražajo svoje spretnosti, znanja in izkušnje (Stebbins, 2002, 3). Izraz se torej nanaša na prostočasne dejavnosti, ki od posameznikov zahtevajo veliko truda, da jih resnično obvladajo. Stebbins (2002, 9-10) navaja številne kompenzacije za vložek časa, truda in nenazadnje tudi denarja za nakup opreme, ki jih ob prostočasnih dejavnostih dobijo posamezniki. Nekatere so povsem osebne, denimo samoaktualizacija ob razvoju spretnosti in znanj, izboljšanje samopodobe ob prikazovanju znanja, samonagrajevanje $\mathrm{z}$ užitkom in rekreacija ob opravljenem delu, ob tem pa omenja še občasno finančno povračilo. Poleg osebnih nadomestil obstajajo še družbene nagrade, kot so širjenje socialnih omrežij ob druženju s somišljeniki in zadovoljstvo ob vzajemnem delu ter ohranjanju in razvoju skupine. Ljudi, ki "prakticirajo« resen prosti čas, zaznamuje tudi vzpon kariere, s čimer je povezano še doseganje statusa, ko drugi priznavajo posameznikove dosežke.

V DOPPS je takšen vzpon kariere precej pogost, saj ornitologija po eni strani omogoča nenehno kopičenje znanj in veščin za opazovanje ptic (prepoznavanje ptičjih 
vrst po videzu, oglašanju itd.), naravovarstvo pa po drugi strani pušča odprta vrata za prostovoljska prizadevanja najbolj entuziastičnih posameznikov. Strmo kariero $\mathrm{v}$ ljubiteljski ornitologiji je, denimo, imel član DOPPS, ki je bil v času raziskave na društvu zaposlen in ga je ena od sogovornic opisala kot "srce društva«, in sicer zaradi številnih dejavnosti, ki jih opravi z dobršno mero entuziazma, pri čemer zna navdušiti in spodbuditi tudi ostale člane in zaposlene. Z društvom se je seznanil v zgodnjih devetdesetih letih 20. stoletja, ko so še izvajali štetja za ornitološki atlas. Na DOPPS so hitro spoznali, da je novinec zelo izurjen v ornitologiji in da je samostojno zbral veliko podatkov o pticah, še posebej o koconogih kurah (na primer o divjem petelinu in ruševcu) v Triglavskem narodnem parku, ti podatki pa so bili v času popisov za atlas dragoceni. Znanje o pticah je pridobil predvsem doma, saj je njegov oče delal v Triglavskem narodnem parku, njihov družinski prijatelj pa je bil gozdar, nekdanji lovec in navdušen fotograf divjih živali. Ko je bil še najstnik, je večino koncev tedna prebil pri tem prijatelju in skupaj sta poskušala napraviti čim boljše fotografije ptic. To znanje mu je omogočilo, da se je najprej profiliral v prostovoljski ekipi, nato postal član društvenega upravnega odbora, nazadnje pa se je zaposlil v pisarni, kjer je prevzel koordiniranje novega ornitološkega atlasa gnezdilk.

Podobno kariero, ki je vodila od prostovoljstva do profesionalnega dela, je imela tudi sodelavka društvene pisarne, ki je bila v času intervjuja stara približno trideset let. Že pri devetih letih se je s pomočjo staršev, ki so spodbujali njeno zanimanje za ptice in naravo, včlanila v DOPPS ter se odtlej občasno udeleževala društvenih izletov, čeprav ji je bilo spočetka »blazno nerodno priti na društvo«, saj tam ni imela vrstnikov. $\mathrm{V}$ osnovni šoli je zanimanje njenih sošolcev in sošolk za naravo in ptice nekoliko uplahnilo, njo pa so te živali še vedno zanimale, zato je bila pri svojem zanimanju precej osamljena. Kot srednješolka je imela še več težav pri iskanju somišljenikov, saj so jo zaradi nenavadnega hobija - opazovanja ptic - imeli za »čudakinjo«, zaradi česar svoje prostočasne dejavnosti sicer ni skrivala, izpostavljala pa je tudi ni več. Šele med študijem biologije je na fakulteti naletela na vrstnike s podobnimi interesi, ki jih je prepričala, da so se udeležili ornitoloških izletov. Tedaj je bila že zelo aktivna članica DOPPS ter je vodila izlete in pomagala pri izvedbi drugih društvenih dejavnosti. Ko je končala diplomo, so jo povabili, naj se zaposli na društvu. To jo je po njenih besedah privedlo v nenavadno situacijo, saj je dotedanji hobi nenadoma postal delo. Zato ni nenavadno, da svoj poklic opisuje kot »sanjsko službo«, ki jo še vedno veseli in izpolnjuje.

Iz številnih drugih podobnih primerov, evidentiranih v DOPPS, je razvidno, da je od resnega prostega časa, s katerim se vzpostavlja prostovoljska oziroma ljubiteljska kariera, le korak do tega, da se oseba, ki se intenzivno ukvarja s hobijem, zaposli v organizaciji in postane oboževalec dela, kar je dejansko nadgradnja »resnega prostega 
časa «. V knjigi Med delom in prostim časom Stebbins pojasnjuje, da takšne ljudi, ki se v celoti predajo poklicu, »motivira oboževanje dela, ki pomeni močno pozitivno povezanost $\mathrm{z}$ delom, pri katerem se izpopolnjujemo in ki nam daje občutek uspešnosti, temeljna dejavnost (niz opravil) pa je pri njem tako privlačna, da ločnica med delom in prostim časom dobesedno izgine« (Stebbins, 2004, 2, poudarek v izvirniku). Sočasno izginja tudi ločnica med organizacijo in skupnostjo, ki se lahko prepletata v enotni dinamični podobi.

\section{Organizacija, skupnost ali omrežje?}

Po eni strani lahko na društvo, ki ga sestavljajo »oboževalci dela«, gledamo kot na skupnost prostovoljcev, povezanih $\mathrm{z}$ enotnim vrednostnim sistemom (varovanje narave, opazovanje ptic). Po drugi strani pa lahko DOPPS razumemo kot organizacijo, v kateri so razmerja moči jasno definirana, hierarhija je transparentna, organizacijska struktura pa pregledna. Na društvo lahko očitno pogledamo tako $\mathrm{z}$ vidika »klasičnih« teorij o organizacijah, ki pojasnjujejo, zakaj in kako v družbi nastane red, kot tudi $\mathrm{Z}$ vidika teorij o skupnostih in omrežjih, ki razlagajo, da so razmerja v egalitarni skupnosti tako kompleksna in fluidna, da jih ne moremo predstaviti s poenostavljenimi in preglednimi idealnotipskimi modeli. Kot kaže, lahko ti dve družbeni obliki celo soobstajata, kar smo videli na primeru DOPPS, ki se je po transformaciji ob koncu devetdesetih let 20. stoletja preobrazil v preplet organizacije in skupnosti, le da takšne strukture ne moremo prikazati s tradicionalnim dvodimenzionalnim organigramom (primerjaj Hock, 1999, 296, kjer piše o večdimenzionalnih modelih t. i. kaordičnih organizacij, ki nekoliko spominjajo na organiziranost nevronov v možganih), temveč si ga lahko predstavljamo kvečjemu kot tridimenzionalni model, ki nekoliko spominja na »palačinko s konico« (slika 1).

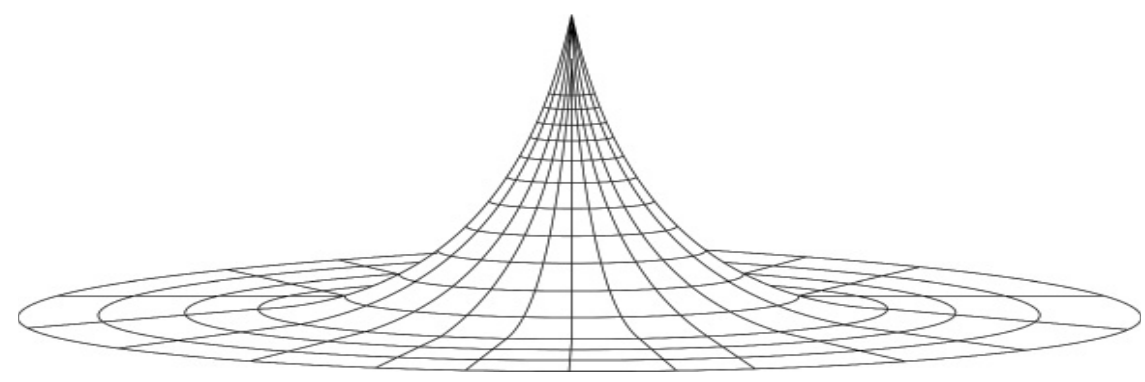

Slika 1: Upodobitev skupnizacije. 
»Palačinka« v tem prikazu predstavlja omrežje prostovoljcev oziroma skupnost bolj ali manj enakovrednih posameznikov, ki so medsebojno prepleteni in povezani. $\mathrm{Na}$ dvodimenzionalnem modelu jih lahko prikažemo kot skupino točk, povezanih z daljicami, ki prikazujejo razmerja med njimi. »Konico«, ki se vzpenja nad omrežjem, pa lahko opišemo s klasičnim organigramom, ki upodablja jasno strukturirano hierarhijo razmerij med posamezniki. Ko sliki združimo, dobimo tridimenzionalno podobo, ki povezuje hierarhično (vertikalno) organizacijo in enakopravno (horizontalno) omrežje oziroma skupnost (slika 2).

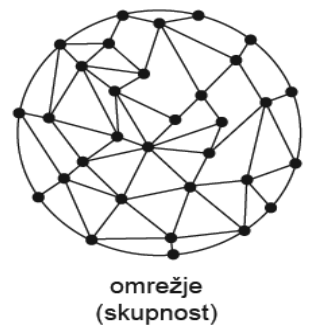

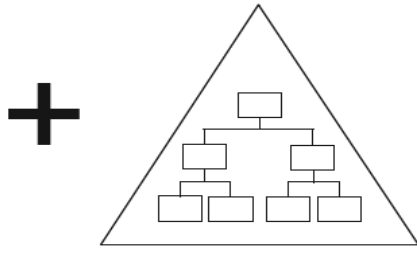

organizacija
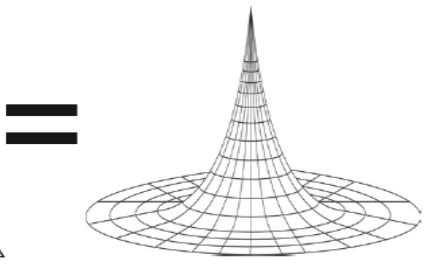

skupnizacija

Slika 2: Skupnizacija kot seštevek skupnosti (omrežja) in organizacije.

Tako smo upodobili skupnizacijo, v kateri se prepletata skupnost in organizacija. Takšna "novotvorba« združuje lastnosti organizacije, omrežja in skupnosti, saj je sočasno urejena in neurejena, stabilna in fleksibilna, omejena in odprta ... Parkerjeva skupnizacija je, z eno besedo, kaordična (primerjaj Hock, 1999). S takšne perspektive so nam bolj jasni in smiselni, denimo, notranji boji, opozicije, sektaštva, delitve - pa tudi njihov konstruktivni pomen. Hkrati bolje razumemo in lažje sprejmemo, da je »organizacijsko življenje prej nedoločljivo, raznoliko in kaotično kot pa preprosto, sistematično, monološko in hierarhično« (Boje, 1995, 1001). Poleg tega se sprijaznimo še $\mathrm{z}$ dejstvom, da organizacije predvsem vzdržujejo navidezni red, dejansko pa v njih vladajo zmeda, zmešnjava, kaos in nered, kar znajo njihovi člani dobro zamaskirati in uprizoriti sožitje (Batteau, 2000, 728).

\section{Sklep}

DOPPS lahko, kot smo videli v prispevku, razumemo kot preplet ideal(izira)ne organizacije (formalne organizacije) in dejanskega kompleksnega omrežja povezav med posamezniki, povezanimi v skupnost (neformalne organizacije). Ko se na ta način zazremo v organizacijo, se nam zazdi, da dve podobi preskakujeta med sabo: za hip je organizacija, nato omrežje ali skupnost, zatem spet organizacija ... Organizacija torej soobstaja in se simbiotično dopolnjuje z omrežjem ali skupnostjo kot entiteta, ki ji pravimo skupnizacija. 
Temeljni pogoj za njen nastanek je platforma oziroma način sodelovanja med dvema različnima konceptoma ali celo ideologijama. Samoorganizirana skupina ljudi, ki nastane iz amorfne množice, se v marsičem razlikuje od organizacij, katerih struktura je navadno povezana $\mathrm{z}$ dominacijo in hierarhijo (Morgan, 2004, 267-304). Struktura skupnosti in omrežij namreč ni jasno definirana, hierarhija pa je tako fluidna, da jo je težko natančno definirati. Dinamičnost in spremenljivost sta zato konstanti skupnizacije, ki pa lahko zaradi organiziranega »jedra«, prepletenega $z$ omrežjem oziroma skupnostjo prostovoljcev, uspešno deluje, čeprav se zdi to skoraj nemogoče $\mathrm{v}$ množici različnih mnenj, idej in ciljev, ki jih imajo ljudje v takšni združbi. Nekaj podobnega opazimo v DOPPS. Vsak posameznik lahko po svoje interpretira društvene cilje ter se pridružuje različnim skupinam in pobudam oziroma deluje v različnih sekcijah. Kljub temu društvo deluje kot celota ter dosega skupne fleksibilne in razmeroma ohlapne cilje, utemeljene na altruizmu in prostovoljstvu - sprva sta bila takšna cilja predvsem opazovanje in proučevanje ptic, nato pa so postavili v ospredje še varovanje ptic in njihovih življenjskih prostorov. S takšnimi preprostimi temeljnimi predpostavkami (izhodiščnimi načeli sodelovanja), ki jih utrjuje, usmerja in deloma spreminja tudi profesionalna ekipa, se ohranja kompleksna in dinamična struktura skupnizacije, ki tako ni več idealnotipska in utopična struktura, temveč predstavlja participativni model, katerega specifike se lahko razkrijejo in aplicirajo v drugih nepridobitnih organizacijah, predstavljene zamisli pa se lahko cum grano salis uporabijo tudi v pridobitnem sektorju - posebej če se otresejo Parkerjevih nekoliko romantičnih in utopičnih predstav ter se osredotočijo predvsem na vzpostavljanje ravnotežja med participativno skupnostjo in urejeno organizacijo.

\section{Literatura}

Ahačič, M., Ptic nisem nikdar opazoval in proučeval za kratek čas, Svet ptic 14 (2), 2008, str. 38-40.

Anderson, B., Zamišljene skupnosti: O izvoru in širjenju nacionalizma, Ljubljana 2003 (1983).

Batteau, A. W., Negations and Ambiguities in the Cultures of Organization, American Anthropologist 102 (4), 2000, str. 726-740.

BirdLife, 2014, BirdLife Global Partnership, http://www.birdlife.org/worldwide/ global/index.html [7. 1. 2014].

Boissevain, J., Mitchell, J. C. (ur.), Network Analysis: Studies in Human Interaction, Haag, Pariz 1973.

Boje, D. M., Stories of the Storytelling Organization: A Postmodern Analysis of Disney as "Tamara-Land «, Academy of Management Journal 38 (4), 1995, str. 997-1035. 
Brumen, B., Umišljena tradicija »dobrih starih časov«, v: Zemljevidi časa / Maps of Time (ur. Šmitek, Z., Brumen, B.), Ljubljana 2001, str. 193-207.

Castells, M., The Rise of Network Society, Oxford 2003 (1996).

Cohen, A. P., Symbolic Construction of Community, London, New York 1985.

Czarniawska-Joerges, B., Exploring Complex Organizations: A Cultural Perspective, Newbury Park, London, New Delhi 1992.

Durkheim, E., The Division of Labor in Society, New York 1997 (1893).

Ford, R. C., Armandi, B. R., Heaton, C. P., Organization Theory: An Integrative Approach, New York 1988.

Granovetter, M., The Strength of Weak Ties, American Journal of Sociology 78 (6), 1973, str. 1360-1380.

Green, S., Harvey, P., Knox, H., Scales of Place and Networks: An Ethnography of the Imperative to Connect through Information and Communications Technologies, Current Anthropology 46 (5), 2005, str. 805-826.

Hamada, T., Anthropology and Organizational Culture, v: Anthropological Perspectives on Organizational Culture (ur. Hamada, T., Sibley, W. E.), Lanham, New York, London 1994.

Hock, D., Birth of the Chaordic Age, San Francisco 1999.

IO DOPPS, Program dela Društva v letu 1985, Acrocephalus 5 (22), 1984, str. 69.

IO DOPPS, Društveni program za leto 1986, Acrocephalus 7 (27/28), 1986, str. 24.

IO DOPPS, Društveni program za leto 1987, Acrocephalus 8 (31/32), 1987, str. 28.

Katz, D., Kahn, R., Organizations and the System Concept, v: Perspectives on Behavior in Organizations, 2. izdaja (ur. J. R. Hackman, Lawler, E. E., Porter, L. W.), New York 1983.

Kimovec, J., Marketinški vidik družbene odgovornosti: Primer Mobitela in DOPPS-a. Diplomsko delo, Univerza v Ljubljani, 2008, neobj.

Leach, E., Political Systems of Highland Burma: A Study of Kachin Social Structure, London 1993 (1954).

Mintzberg, H., The Structuring of Organizations: A Synthesis of the Research, London itd. 1979.

Mintzberg, H., van der Heyden, L., Organigraphs: Drawing How Companies Really Work, Harvard Business Review 77 (5), 1999, str. 87-94.

Mitchell, J. C. (ur.), Social Networks in Urban Situations: Analyses of Personal Relationships in Central African Towns, Manchester 1969.

Mitchell, J. C., Social Networks, Annual Review of Anthropology 3, 1974, str. 279-299. 
Molina, J. L., The Informal Organizational Chart in Organizations: An Approach from the Social Network Analysis, Gazeto Internacia de Antropologio 1, 2006, str. 32-45.

Morgan, G., Podobe organizacij, Ljubljana 2004.

Parker, M., Organisation, Community and Utopia, Studies in Cultures, Organizations and Societies 4 (1), 1998, str. 71-91.

Parker, M., Organizational Culture and Identity: Unity and Division at Work, London, Thousand Oaks, New Delhi 2000.

Podjed, D., Antropološki vidiki postmoderne organizacije, Organizacija 39 (9), 2006, str. 585-590.

Podjed, D., Organizacijski kristal: Karizmatični vodja kot pobudnik prostovoljstva v organizaciji, Traditiones 39 (2), 2010, str. 107-123.

Podjed, D., Opazovanje opazovalcev: Antropološki pogled na ornitološko organizacijo, Ljubljana 2011.

Podjed, D., De l'observation à la protection des oiseaux: Le tournant vers la protection de la nature chez les ornithologues amateurs slovènes, Revue d'Anthropologie des Connaissances 7 (2), 2013, str. 113-135.

Radcliffe-Brown, A., On Social Structure, The Journal of the Royal Anthropological Institute of Great Britain and Ireland, 70 (1), 1940, str. 1-12.

Robbins, S. P., Organizational Behaviour: Concepts, Controversies, Applications, 7. izdaja, Englewood Cliffs 1996.

Schwartzman, H., Ethnography in Organizations, Newbury Park, London, New Delhi 1993.

Schein, E., Organizational Culture and Leadership, 2. izdaja, San Francisco 1992.

Schutz, A., The Phenomenology of the Social World, Evanston 1972.

Simmel, G., Georg Simmel on Individuality and Social Forms: Selected Writings, Chicago 1971.

Stebbins, R., Amateurs, Professionals, and Serious Leisure, Montreal 2002.

Stebbins, R., Between Work and Leisure: The Common Ground of Two Separate Worlds, New Brunswick, London 2004.

Stebbins, R., Serious Leisure: A Perspective of Our Time, New Brunswick, London 2006.

Šalaja, N., LIFE, ki je več kot življenje, Svet ptic 10 (4), 2004, str. 24-25.

Tönnies, F., Skupnost in družba: Temeljni pojmi čiste sociologije, Ljubljana 1999 (1887). 
Turner, V., The Ritual Process: Structure and Anti-Structure, Harmondsworth 1974.

Weber, M., Economy and Society: An Outline of Interpretive Sociology, Berkeley, Los Angeles, London 1978 (1921).

Wolfe, A. W., The Rise of Network Thinking in Anthropology, Social Networks 1, 1978, str. 53-64. 
Dan Podjed

\section{Skupnizacija kot seštevek skupnosti in organizacije: Primer ornitološkega in naravovarstvenega društva}

Ključne besede: organizacija, skupnost, omrežje, ornitološko društvo, varovanje narave

Prispevek, ki je nastal na podlagi etnografske raziskave, osvetli dinamiko razmerij $\mathrm{v}$ slovenskem ornitološkem in naravovarstvenem društvu DOPPS, v katerem se prepletajo prostovoljske in profesionalne dejavnosti. Na primeru društva prikaže konfliktna razmerja med skupinami, hkrati pa opiše recipročnost in sodelovanje ter poenotenje kulturnih predpostavk, ki so pomembne za doseganje skupnih ciljev. Avtor ugotavlja, da nestabilna in nasprotujoča si razmerja v društvu utemeljujejo nenavaden preplet med hierarhično organizacijo in egalitarno skupnostjo, ki jo britanski socialni antropolog Martin Parker imenuje »skupnizacija«. Takšna družbena oblika je sicer strukturirana in organizirana, a hkrati utemeljena na rudimentarni pripadnosti in solidarnosti njenih članov. Meja med delom in prostim časom je v njej v dobršni meri zabrisana, hierarhična razmerja niso jasna in poudarjena, njeni člani imajo enak delež pri produkciji in dejavnostih, vanjo rekrutirajo predvsem enako misleče posameznike, odločanje v njej pa poteka počasi in z demokratičnimi procesi. Številne od teh lastnosti najdemo v DOPPS, ki deluje kot preplet organizacije in omrežja oziroma skupnosti. Organizacija torej soobstaja in se simbiotično dopolnjuje $\mathrm{z}$ omrežjem ali skupnostjo kot entiteta, ki je ne moremo upodobiti s preprostim dvodimenzionalnim modelom (organigramom). $\mathrm{V}$ njej se namreč prepletata dva modela sodelovanja, in sicer hierarhična organizacija s "piramidalno« strukturo ter horizontalna skupnost oziroma omrežje prostovoljcev, v katerem se razmerja nenehno na novo definirajo. 
Dan Podjed

\section{Orgunity as the sum of organisation and community: An example of Ornithological Society and Nature Conservation Association}

Keywords: organisation, community, network, ornithological society, nature conservation

The article, based on ethnographic research, highlights the dynamics of relationships in DOPPS, the Slovenian ornithological and nature conservation society, and describes a mixture of voluntary and professional activities in the organization. The article also addresses the conflicts among different groups that exist within DOPPS and describes the reciprocity, cooperation and unification of the cultural assumptions which are important for achieving common goals. The author claims that unstable and conflicting relationships in the association have led to a unique combination of hierarchical organization and egalitarian community. The British social anthropologist Martin Parker names this combination "orgunity". Though structured and organized, a social form of this kind is based on the rudimentary affiliation and solidarity of its members. The boundary between work and leisure is blurred, hierarchical relationships are not clearly defined, members contribute equally to the production of the group and to various activities, mainly like-minded individuals are recruited, decision-making is carried out at a slow pace and on the basis of democratic processes, etc. Many of these characteristics can be seen in DOPPS, which functions as an amalgamation of an organization and a network or a community. The organization therefore complements the symbiotic network or community and creates an entity that cannot be illustrated with a simple two-dimensional model such as organizational chart. Two models of cooperation are intertwined in an orgunity: a hierarchical organization with a pyramid structure and a horizontal community or a network of volunteers in which relationships are constantly redefined. 